\title{
The Establishment of China Bronchiectasis Registry and Research Collaboration (BE-China): Protocol of a prospective multicenter observational study
}

\author{
Yonghua Gao \\ Tongji University School of Medicine \\ Hai-Wen Lu \\ Tongji University School of Medicine

\section{Bei Mao} \\ Tongji University School of Medicine \\ Weijie Guan \\ The First Affiliated Hospital of Guangzhou Medical University \\ Yuan-Lin Song \\ Fudan University

\section{Yuan-Yuan Li} \\ Central South University

\section{Dao-Xin Wang} \\ The Second Affiliated Hospital of Chongqing Medical University

\section{Bin Wang} \\ Huzhou Central Hospital

\section{Hong-Yan Gu} \\ The Sixth People's Hospital of Nantong

\section{Wen Li} \\ Second Affiliated Hospital of Zhejiang University School of Medicine

\section{Hong Luo} \\ Central South University

\section{Ling-Wei Wang} \\ Shenzhen People's Hospital
}

Fan Li

Songjiang District Central Hospital

\section{Feng-Xia Guo}

The Eighth People's Hospital of Shanghai

\section{Min Zhang}

Shanghai Jiao Tong University School of Medicine

Zhi-Jun Jie

Fudan University

Jing-Qing Hang

Shanghai Putuo District People's Hospital

\section{Chao Yang}

Suzhou Science and Technology Town Hospital

\section{Tao Ren}

Shanghai Jiao Tong University Affiliated Sixth People's Hospital 


\section{Zhi Yuan}

Fenghua District People's Hospital

\section{Qing-Wei Meng}

Shangrao People's Hospital

\section{Qin Jia}

Shidong Hospital of Yangpu District

\section{Yu Chen}

China Medical University

\section{Rong-Chang Chen}

Shenzhen People's Hospital

\section{Jie-Ming Qu}

Ruijin Hospital, Shanghai Jiaotong University School of Medicine

Jin-Fu Xu ( $\square$ jfxu@tongji.edu.cn )

Tongji University School of Medicine

\section{Study protocol}

\section{Keywords:}

Posted Date: February 23rd, 2022

DOI: https://doi.org/10.21203/rs.3.rs-1374855/v1

License: (c) (1) This work is licensed under a Creative Commons Attribution 4.0 International License. Read Full License 


\section{Abstract}

\section{Background}

Bronchiectasis is a highly heterogeneous chronic airway disease with marked geographic and ethnic variations. Most influential cohort studies to date have been performed in Europe and USA, which serve as the examples for developing a cohort study in China where there is a high burden of bronchiectasis. The Establishment of China Bronchiectasis Registry and Research Collaboration (BE-China) is designed to: (1) describe the clinical characteristics and natural history of bronchiectasis in China and identify the differences of bronchiectasis between the western countries and China; (2) identify the risk factors associated with disease progression in Chinese population; (3) elucidate the phenotype and endotype of bronchiectasis by integrating the genome, microbiome, proteome, and transcriptome with detailed clinical data; (4) facilitate large randomized controlled trials in China.

Methods and design:

The BE-China is an ongoing prospective, longitudinal, multi-center, observational cohort study which aims to recruit a minimum of 10,000 patients, which was initiated in January 2020 in China. Comprehensive data, including medical history, aetiological testing, lung function, microbiological profiles, radiological scores, comorbidities, mental status, and quality of life (QoL), will be collected at baseline. Patients will be followed up annually for up to 10 years to record longitudinal data on outcomes, treatment patterns and QoL. Biospecimens, if possible, will be collected and stored at $-80^{\circ} \mathrm{C}$ for further research. Up to October 2021, the BE-China has enrolled 3758 patients from 91 medical centers. The study protocol has been approved by the Shanghai Pulmonary Hospital ethics committee, and all collaborating centers received approvals from their local ethics committee. All patients provided written informed consent to their participation.

\section{Conclusions}

Findings of the BE-China will be crucial to reveal the clinical characteristics and natural history of bronchiectasis and facilitate evidence-based clinical practice in China.

\section{Registration Number in ClinicalTrials.gov: NCT03643653}

\section{Introduction}

Bronchiectasis has been historically neglected due to the assumption that extensive use of antibiotics would help eradicate bronchiectasis [1]. However, the expected decline in bronchiectasis has not occurred, and the number of patients has risen in the past decade possibly owing to the aging populations and the extended use of high-resolution computed tomography (HRCT) [2,3]. Thus, bronchiectasis is posing an increasing burden on healthcare systems around the world with an effect on patient's quality of life (QoL) and survival [2,3], suggesting an urgent need for better resourced research into this condition.

An upsurged interest in recent years has transformed the field of bronchiectasis. We now have clearer definitions and classifications of the disease [4], specific QoL tools [5,6], multidimensional severity assessment tools [7-10], and more robust evidence-based treatments such as airway clearance, macrolides, and inhaled antibiotics [11-16]. Everyone within the field would agree that large-scale registries with regular and long-term follow-up, such as EMBARC (European Multicenter Bronchiectasis Audit and Research Collaboration) and US bronchiectasis registry, have made a major contribution to these advances $[17,18]$. However, most publications to date have only focused on large cohorts of bronchiectasis patients originating from Europe and the USA. It is clear that more data are required from Asia, especially from China - the most populous country $[19,20]$. Recently, national registries have been established in Korea and India, which will add more evidence to the Asian phenotypes of bronchiectasis [21,22]. Emerging data have shown that there may be substantial differences between Asian patients and western patients regarding the aetiology, microbiological profiles, disease severity and comorbidities [22-24]. However, the characteristics of bronchiectasis may vary according to the country and socioeconomic status of the targeted population [23]. The Establishment of China Bronchiectasis Registry and Research Collaboration (BE- 
China) would allow us to better understand the characterization of Chinese bronchiectasis patients and test whether the phenotypes identified in western cohorts could be validated in China, which could provide valuable insights into geographical and ethnic differences of bronchiectasis.

The heterogeneity of bronchiectasis remains the greatest clinical challenge [1]. Currently, there are no licensed therapies for bronchiectasis and the clinical trials in bronchiectasis have been largely unsuccessful possibly due to the poor understanding of the pathophysiology. Biospecimens are invaluable clinical research resources for genetic and molecular studies to reveal the endotype and pathogenesis. Therefore, the development of bioresources embedded in registry as a backbone to build a repository of blood, sputum and other biological materials for use in translational research, will help us to better understand the pathophysiology of bronchiectasis, to better phenotype patients and individualize their management. EMBARC has made a substantial contribution to the translational research in bronchiectasis in the past few years [25-27], but we still have a long way to fully understand this disease or offer the evidence-based personalized management for patients with bronchiectasis. Additional state-of-art biobank, outside of western populations, is vital for further microbiome, proteome, genome and transcriptome research due to the potentially varying genetic background and molecular characteristics among patients from different geographic regions.

The BE-China was formally initiated since January 2020, which is the only large prospective, multicenter, longitudinal cohort study in bronchiectasis across China. The BE-China will recruit eligible individual bronchiectasis patients, and comprehensively collect their clinical data, as well as biospecimens with longitudinal follow up for future research. Herein, we describe the rational and design of the BE-China registry.

\section{Methods An Analyses}

\section{Study design and objectives}

The BE-China registry, which was initiated in January 2020, is a Yangtze River Delta region-based nationwide, multicenter, prospective, longitudinal, observational cohort study which aimed to enroll a minimum of 10,000 consecutive adult patients with radiologically confirmed bronchiectasis in China. Enrolled patients are managed by trained and certified local physicians in each participating center according to clinical practice and guidelines without imposed interventions. The number of participating centers and their locations are shown in Figure 1.

Comprehensive data, including demographics, medical history, comorbidities, aetiological testing, lung function, echocardiography, microbiological profiles in sputum or bronchoalveolar lavage fluid (BALF), radiological scores, QoL and treatment, are collected at baseline (recruitment) during steady-state. The patients will be followed up to ten years on annual basis (within a three-month variance) aligned to routine clinical attendance. In addition, recruiting centers with access to appropriate facilities are encouraged to biobank sputum, serum, plasma, blood cells, BALF and lung tissue, if possible, both at steady-state and exacerbation. Design of the study are present in Figure 2.

The main objectives of the BE-China are to:

1. characterize the demographics, aetiology, lung function, microbiological profiles, exacerbation, disease severity, QoL and treatment of Chinese bronchiectasis patients;

2. validate the phenotype of bronchiectasis identified in Western cohorts and figure out the differences between China and the Western countries;

3. elucidate the risk factors associated with deteriorating QoL, rapid decline of lung function, frequent exacerbation, and mortality;

4. reveal the natural history of bronchiectasis with defined aetiology (such as allergic bronchopulmonary aspergillosis, tuberculosis, and connective tissue disease); 
5. explore the new bronchiectasis phenotype and endotype of stable disease and exacerbation through integrating the clinical data, microbiome, proteomics, and genomics in China;

6. facilitate large-scale randomized controlled trials in China.

\section{Participants, inclusion and exclusion criteria}

The inclusion criteria of this registry are: (1) patients aged 18 years or older with a clinical history consistent with bronchiectasis (cough, chronic sputum production, and a history of exacerbations) and having chest HRCT in the past one year indicating bronchiectasis affecting one or more lobes; (2) remaining clinically stable when recruitment. Patients with exacerbation are allowed to enroll into the registry at least 4 weeks after antibiotic discontinuation.

The exclusion criteria are as follows: (1) traction bronchiectasis associated with interstitial lung disease or other pulmonary disorders; (2) cystic fibrosis associated bronchiectasis; (3) patients who are unable or unwilling to provide informed consent.

\section{Biospecimens and biobank}

Samples will be bio-banked in each individual center if appropriate facilities are available. Blood, sputum, BALF and lung tissue samples of enrolled patients who are able to provide consent are collected via local well-trained investigators according to critical standard operating procedure. The blood will be centrifuged, and divided into three aliquots (plasma, serum, or blood cells, respectively). Unprocessed spontaneous sputum will be aliquoted. Per protocol, among patients with diffuse bronchiectasis, BALF samples was conducted in the right middle lobe or left lingula lobe. In the case of localized bronchiectasis, the targeted segment was chosen based on chest HRCT scan. BALF samples were centrifuged for 20min at $3184 \mathrm{~g}$ at $4^{\circ} \mathrm{C}$. The supernatant was then divided into aliquots. And aliquoted blood, sputum, lung tissue, BALF supernatant and cell pellets will be stored at $-80^{\circ} \mathrm{C}$ for further genetic, proteomic and microbiome analyses. Participants can still be enrolled into the registry platform even if they are unable to provide samples.

\section{Data collection}

Three parts of data are collected in BE-China Registry: (1) baseline data; (2) annual follow-up data; (3) data at exacerbation. Detailed information are described as follows (Table 1):

\section{(1) Health-related QoL}

The registry will use both "QoL-Bronchiectasis" questionnaire (QoL-B) and Bronchiectasis Health Questionnaire (BHQ) to evaluate QoL $[5,6]$. Both questionnaires are the disease-specific QoL tools that have been specially developed and validated for use in bronchiectasis. The Hospital Anxiety and Depression Scale is employed to evaluate the status of anxiety and depression in patients with bronchiectasis [28]. Gastroesophageal reflux disease questionnaire (Gerd-Q) is used to diagnose the gastroesophageal reflux disease in patients with bronchiectasis as the potential aetiology or comorbidity [29]. An automatic calculator tool of these questionnaires is incorporated into the registry platform to aid in the calculation.

\section{(2) Leicester Cough Questionnaire (LCQ)}

We have included the LCQ in our registry because it has been validated in bronchiectasis [30,31]. Cough was rated as one of the most troublesome symptom in bronchiectasis by most patients in a survey of 711 European patients with bronchiectasis [32]. Inclusion of this questionnaire will also allow comparison to other datasets.

\section{(3) Aetiology of bronchiectasis}

The physicians caring for the patient will determine the aetiology of bronchiectasis based on medical history, extensive aetiological testing, and questionnaires. Items of aetiological testing follow the recommendation by national and international guidelines [11-13], with blood cell counts, serum immunoglobulins (Ig) (total $\lg G$, IgA and $\lg M$ ), and testing for allergic bronchopulmonary aspergillosis (ABPA) (total serum IgE, specific IgE to Aspergillus etc) as the mandatory testing. Other 
aetiologial tests, including autoimmune disease, alpha one antitrypsin deficiency, cystic fibrosis, primary ciliary dyskinesia, are carried out in patients with suggestive clinical features determined by local physicians.

\section{(4) Exacerbations}

We define the exacerbations based on the criteria recommended by EMBARC consensus [33]. Exacerbations are defined as deterioration of three or more following symptoms for at least 48 hours which require an immediate change of routine treatment: (1) cough; (2) sputum volume increase and/or consistent change; (3) sputum purulence; (4) dyspnea and/or exercise intolerance; (5) fatigue and/or malaise; (6) hemoptysis. Severe exacerbations are defined as exacerbations requiring an emergency room visit or hospitalization.

\section{(5) Sputum assessment}

Sputum colour is assessed using a validated photographic sputum colour chart that is graded as 1 (mucoid) to 4 (highly purulent) [34]. Sputum volume ( $\mathrm{mL} /$ day) is estimated by patients' report.

\section{(6) Spirometry}

Pre-bronchodilator and post-bronchodilator spirometry are performed according to American Thoracic Society (ATS)/European Respiratory Society (ERS) guidelines [35]. The percentage of predicted values for forced expiratory volume in one second $\left(\mathrm{FEV}_{1}\right)$ and forced vital capacity $(\mathrm{FVC})$ will be calculated by using a reference equation of Chinese people. In addition, total lung capacity, residual volume, inspiratory capacity, small airway function, or diffusion function assessed by spirometry are also collected when available.

\section{(7) Microbiological profiles}

The microbiological profiles from any sample (sputum, BALF or induced sputum) will be recorded either at steady-state or exacerbation. In addition, the data of fungi and non-tuberculous mycobacterium, including individual species, will be also collected.

\section{(8) Disease severity}

Both the Bronchiectasis Severity Index (BSI) and E-FACED are employed to assess the severity of bronchiectasis based on each variables [7-10], with the total scores being calculated automatically at database platform.

\section{(9) Comorbidities}

Both pulmonary and extrapulmonary comorbidities are carefully collected [36]. Regarding pulmonary comorbidities, we record the presence or absence of physician-diagnosed asthma, chronic obstructive pulmonary disease (COPD), rhinitis, chronic sinusitis and nasal polyp. Extrapulmonary comorbidities, including cardiovascular diseases, stroke, digestive diseases, endocrine diseases, hematological diseases, renal diseases, rheumatoid diseases, malignancy (including tumor sites) and immunodeficiency types will be recorded.

\section{(10) Radiology}

We use both the modified Reiff score and Bhalla score to assess the radiological severity of bronchiectasis [7,37]. Physicians in each center determine the radiological score independently after careful training. Furthermore, images of chest CT scans at specific sites are required to be uploaded to the database platform for future use.

\section{(11) Echocardiography}

Echocardiography will be used to evaluate the left and right cardiac function in bronchiectasis. Patients with cardiac dysfunction or pulmonary hypertension are at great risk of death in bronchiectasis [38], which are not uncommonly seen in 
China.

\section{(12) Treatments}

Regular treatment associated with bronchiectasis are recorded in detail, including airway clearance techniques, antibiotics (oral, inhaled, or nebulized), mucoactive drugs (oral or nebulized), long-acting muscarinic antagonist (LAMA), long-acting $\beta 2$ agonist (LABA), inhaled corticosteroid (ICS), ICS/LABA, LABA/LAMA, ICS/LABA/LAMA. Data on the use of long-term home oxygen therapy, non-invasive ventilation, intravenous Ig, ABPA related treatment (oral corticosteroid, anti-fungi drugs), along with the vaccination status are also collected.

\section{Quality control, data management and monitoring}

The registry collects data via an electronic data capture (EDC) solution which is designed based on the electronic case report form (eCRF). Patient information is de-identified and confidentially collected and then entered into the BE-China platform which was built on a secure website (www.chinabronchiectasis.com). All electronic data are protected by account and passwords.

Several strategies are taken to manage the data and ensure quality control. First, the EDC system and eCRF are designed with built-in logic checks during data entry. Second, each eligible center should designate one or two knowledgeable clinical research coordinators, who have been trained by centralized coordinators according to research protocols, to collect and record patient data in the EDC system to ensure the completeness and accuracy of each entered data. Third, data quality is monitored by a dedicated project and data management team according to predefined procedures. Once abnormal or missing values are detected, queries will be sent by the EDC system automatically to local investigators to check and revise the data. Moreover, research and data quality control report will be generated and circulated to all participating centers and local investigators periodically by Email or Wechart. Each local investigators can access their own data without restrictions. However, complete data analysis requires submission of a research proposal to the BE-China Scientific Committee, and then access can be granted after approval of the research proposal.

\section{Ethics and Dissemination}

Patients will receive regular follow-up at the outpatient clinic or via telephone by the local investigators. All patients signed written informed consent required by the ethics committee according to the Declaration of Helsinki and local regulatory polices at each center. The BE-China has been registered in the Clinicaltrials.gov with an identifier of NCT03643653. The BEChina study group will follow the recommendations regarding authorship provided by the International Committee of Medical Journal Editors. The findings will be disseminated via publication in peer-reviewed journals, conference presentations, or academic website.

\section{Statistical analysis}

All eligible patients will be included in the final analysis. Revealing the clinical characteristics and elucidating the factors that may contribute to the outcomes (such as exacerbation, QoL, and mortality) are the main predefined hypotheses for this registry.

Data are presented as mean (standard deviation, SD), median (interquartile range, IQR) or count (proportion), as appropriate. Categorical variables are compared using chi-squared test. Continuous variables are compared using unpaired t tests or Mann-Whitney test when appropriate. Unadjusted and adjusted analyses are performed using a negative binomial model to determine independent factors and their magnitudes of associations with the frequency of exacerbations and hospitalizations. Time to event outcomes will be presented using Kaplan-Meier methods, and hazard ratios and corresponding $95 \%$ confidence intervals will be modeled using Cox proportional hazards models. Additionally, subgroup analysis will be performed according to different aetiology, age of patients, or sex etc. 


\section{Discussion}

This study is a nationwide prospective multicenter ongoing registry on bronchiectasis, which was formally launched since January 2020 in China, and until November 2021 it has enrolled 3758 potentially eligible patients. The main objective of the study is to describe the cross-sectional spectrum and natural history of bronchiectasis by long-term follow-up, as well as to reveal the phenotypes/endotypes of bronchiectasis and facilitate large randomized controlled trials among Chinese patients.

Many registry studies on bronchiectasis have been established both in western and Asian countries in the past decade [17,21,22,39-42], which significantly improve our understanding on bronchiectasis. As for now, seven ongoing large registry studies [17,21,22,39-42] on bronchiectasis are summarized in Table 2. EMBARC represents the first and largest truly international bronchiectasis network around the world, and thus far it has enrolled more than 19000 bronchiectasis patients who are planned to follow-up up to five years. During the past 10 years, the EMBARC investigators have published more than 70 original paper spanning from aetiology, endophenotypes to disease management of bronchiectasis [18,25-27], and the first international guideline for the management of bronchiectasis [11]. The success of EMBRAC, highlights the importance of establishing the large-scale registry studies with long-term follow up to uncover the heterogeneity of the disease, which could not be achieved by single-center small sample studies. In Asia, India and Korea have built up their registries, which are aligned with EMBARC [21,22]. Pilot data from these registries have demonstrated substantial difference regarding aetiologies, clinical symptoms, disease severity, clinical course, inflammatory profiles and microbiol communities, between Asian and Western countries [22-24-]. However, these registries in Asia, are lack of biospecimens and include a limited number of participants. In addition, previous clinical trials, such as RESPIRE $[43,44]$, in bronchiectasis have demonstrated that patients from different geographic region behaved differently to what was expected with devastating consequences for the trial. This illustrates that the more data about geographic and ethnic differences of bronchiectasis should be clearly addressed.

The designated functions of the BE-China could compensate above unaddressed gaps. This registry comprehensively collects the clinical data of all enrolled patients from steady-state to exacerbation, as well as during annual follow-up, which makes descriptions of natural history of the disease feasible and practical. Disease characteristics and progression could also be compared among different subgroup patients stratified by demographic (i.e. age, gender, body mass index) or clinical features (i.e. aetiology, disease severity, comorbidities). In addition, risk factors that are contributed to poor outcomes (deteriorated QoL, progressive lung function decline, frequent exacerbation, and mortality) and corresponding predicted tool could be determined and validated. Furthermore, we could compare the characteristics, progression patterns and management of bronchiectasis between China and Western countries, or other Asian countries by international collaborations. Also, we will test whether the phenotype and endotype identified in western population could be validated in Chinese patients. The substantial heterogeneity of bronchiectasis underscores the importance of a better mechanistic understanding of its pathology and progression. The biobanking of samples, while matched with detailed clinical data, will allow us to conduct mechanistic research in the future. In short, we believe the BE-China will not only promote research in the epidemiology, aetiology, microbiology, pathophysiology, clinical management and prognosis of bronchiectasis in China, but also facilitate multidisciplinary collaborative research around the world.

Certain limitations should be acknowledged. Since the patients will be mainly enrolled from secondary and tertiary hospitals, it appears that patients may not represent the full profiles of bronchiectasis across China. However, the referral system in China is not strict, and patients can go directly to public hospitals for all outpatients care. The representation of enrolled patients would be not a major concern. In addition, as with any registry study, withdrawal of patients and missing data may result in bias and there may be other unidentified or unmeasured confounding factors.

\section{Conclusions}


In conclusion, BE-China will establish a rich set of clinical and biological data on a large cohort of well-characterized

individuals with bronchiectasis in China. The study will provide unique and detailed insight into disease characteristics and progression among Chinese patients, and lay the foundation for international collaboration in the future.

\section{Abbreviations}

ABPA=Allergic bronchopulmonary aspergillosis;

ATS=American Thoracic Society (ATS);

BALF=Bronchoalveolar lavage fluid;

BE-China=The Establishment of China Bronchiectasis Registry and Research Collaboration;

BHQ=Bronchiectasis Health Questionnaire;

BSI=Bronchiectasis Severity Index;

COPD=Chronic obstructive pulmonary disease;

eCRF= Electronic case report form;

$\mathrm{EDC}=$ Electronic data capture (EDC);

EMBARC= European Multicenter Bronchiectasis Audit and Research Collaboration;

ERS=European Respiratory Society (ERS);

$\mathrm{FEV}_{1}=$ Forced expiratory volume in one second;

FVC=Forced vital capacity;

Gerd-Q=Gastroesophageal reflux disease questionnaire;

HRCT= High-resolution computed tomography;

ICS=Inhaled corticosteroid;

$\lg =$ Immunoglobulin;

$\mathrm{IQR}=$ Interquartile range;

LAMA=Long-acting muscarinic antagonist;

LABA=Long-acting $\beta 2$ agonist (LABA);

LCQ=Leicester Cough Questionnaire;

QoL=Quality of life;

$\mathrm{SD}=$ Standard deviation;

\section{Declarations}


This study received necessary approval from institutional Review Boards of all participating institutions.

\section{Consent for publication}

Not required

\section{Availability of data and materials}

Not applicable

\section{Funding}

This study was supported by National Natural Science Foundation of China (81925001 to JFX), Shanghai Pujiang program 2021 (21PJD061 to YHG), Key Scientific Innovation Project of Shanghai Municipal Education Commission (No. 202101070007-E00097 to JFX) and the Innovation Group Project of Shanghai Pulmonary Hospital.

\section{Competing interests}

All authors declare no competing interests.

\section{Authors' contributions}

YHG and JFX drafted the first version of this manuscript; HWL, BM, WJG, YLS, RCC, JMQ, JFX conceived and designed the overall study; YHG, HWL, BM, WJG, YLS, RCC, JMQ, RCC, JFX are responsible for study oversight, management and coordination. All authors reviewed the manuscript for intellectual content and approved the final version of the report.

\section{Acknowledgements}

The authors would like to thank the participation of all eligible patients with bronchiectasis.

\section{References}

1. Chalmers JD, Chang AB, Chotirmall SH, et al. Bronchiectasis. Nat Rev Dis Primers 2018; 4: 45.

2. Quint JK, Millett ERC, Joshi M, et al. Changes in the incidence, prevalence and mortality of bronchiectasis in the UK from 2004 to 2013: a population-based cohort study. Eur Respir J 2016; 47: 186-193.

3. Ringshausen FC, Roux AD, Diel R, et al. Bronchiectasis in Germany: a population-based estimation of disease prevalence. Eur Respir J 2015; 46: 1805-1807.

4. Aliberti S, Goeminne PC, O'Donnell AE, et al. Criteria and definitions for the radiological and clinical diagnosis of bronchiectasis in adults for use in clinical trials: international consensus recommendations. Lancet Respir Med 2021 Sep 24; S2213-2600(21)00277-0.

5. Quittner AL, Marciel KK, Salathe MA, et al. A preliminary qualify of life questionnaire-bronchiectasis: a patient-reported outcome measure for bronchiectasis. Chest 2014; 146: 437-448.

6. Spinou A, Siegert RJ, Guan WJ, et al. The development and validation of the bronchiectasis health questionnaire. Eur Respir J 2017; 49: 1601532.

7. Chalmers JD, Goeminne P, Aliberti S, et al. The bronchiectasis severity index. An international derivation and validation study. Am J Respir Crit Care Med 2014; 189: 576-585.

8. Martínez-García MÁ, de Gracia J, Vendrell Relat M, et al. Multidimensional approach to non-cystic fibrosis bronchiectasis: the FACED score. Eur Respir J 2014; 43: 1357-1367.

9. Martinez-Garcia MA, Athanazio RA, Girón R, et al. Predicting high risk of exacerbations in bronchiectasis: the E-FACED score. Int J Chron Obstruct Pulmon Dis 2017; 12: 275-284. 
10. Wang H, Ji XB, Li CW, et al. Clinical characteristics and validation of bronchiectasis severity score systems for posttuberculosis bronchiectasis. Clin Respir J 2018; 12: 2346-2353.

11. Polverino E, Goeminne PC, McDonnell MJ, et al. European Respiratory Society guidelines for the management of adult bronchiectasis. Eur Respir J 2017; 50: 1700629.

12. Hill AT, Sullivan AL, Chalmers JD, et al. British Thoracic Society Guideline for bronchiectasis in adults. Thorax 2019; 74(Suppl 1): 1-69.

13. Bronchiectasis Expert Consensus Writing Group; Pulmonary Infection Assembly, Chinese Thoracic Society. Expert consensus on the diagnosis and treatment of adult bronchiectasis in China. Zhonghua Jie He He Hu Xi Za zhi 2021; 44: 311-321.

14. Muñoz G, de Gracia J, Buxó M, et al. Long-term benefits of airway clearance in bronchiectasis: a randomized placebocontrolled trial. Eur Respir J 2018; 51: 1701926.

15. Chalmers JD, Boersma W, Lonergan $\mathrm{M}$, et al. Long-term macrolide antibiotics for the treatment of bronchiectasis in adults: an individual participant data meta-analysis. Lancet Respir Med 2019; 7: 845-854.

16. Laska IF, Crichton ML, Shoemark A, et al. The efficacy and safety of inhaled antibiotics for the treatment of bronchiectasis in adults: a systematic review and meta-analysis. Lancet Respir Med 2019; 7: 855-869.

17. Chalmers JD, Aliberti S, Polverino E, et al. The EMBARC European Bronchiectasis Registry: protocol for an international observational study. ERJ Open Res 2016; 2: 00081.

18. Aliberti S, Polverino E, Chalmers JD, et al. The European Multicentre Bronchiectasis Audit and Research Collaboration (EMBARC) ERS Clinical Research Collaboration. Eur Respir J 2018; 52: 1802074.

19. Wang N, Qu JM, Xu JF. Bronchiectasis management in China, what we can learn from European Respiratory Society Guidelines. Chin Med J (Engl) 2018; 131: 1891-1893.

20. Lin JL, Xu JF, Qu JM. Bronchiectasis in China. Ann Am Thorac Soc 2016; 13: 609-616.

21. Lee $\mathrm{H}$, Choi $\mathrm{H}$, Sim YS, et al. KMBARC registry: protocol for a multicentre observational cohort study on non-cystic fibrosis bronchiectasis in Korea. BMJ Open 2020; 10: e034090.

22. Dhar R, Singh S, Talwar D, et al. Bronchiectasis in India: results from the European Multicentre Bronchiectasis Audit and Research Collaboration (EMBARC) and Respiratory Research Network India Registry. Lancet Glob Health 2019; 7: e1269e1279.

23. Chandrasekaran R, Mac Aogáin M, Chalmers JD, et al. Geographic variation in the aetiology, epidemiology and microbiology of bronchiectasis. BMC Pulm Med 2018; 18: 83.

24. Lee H, Choi H, Chalmers JD, et al. Characteristics of bronchiectasis in Korea: First data from the Korean Multicenter Bronchiectasis Audit and Research Collaboration registry and comparison with other international registries. Respirology 2021; 26: 619-621.

25. Finch S, Shoemark A, Dicker AJ, et al. Pregnancy zone protein is associated with airway infection, neutrophil extracellular trap formation, and disease severity in bronchiectasis. Am J Respir Crit Care Med 2019; 200: 992-1001.

26. Keir HR, Shoemark A, Dicker AJ, et al. Neutrophil extracellular traps, disease severity, and antibiotic response in bronchiectasis: an international, observational, multicohort study. Lancet Respir Med 2021; 9: 873-884.

27. Dicker AJ, Lonergan M, Keir HR, et al. The sputum microbiome and clinical outcomes in patients with bronchiectasis: a prospective observational study. Lancet Respir Med 2021; 9: 885-896.

28. Gao YH, Guan WJ, Zhu YN, et al. Anxiety and depression in adult outpatients with bronchiectasis: Associations with disease severity and health-related quality of life. Clin Respir J 2018; 12: 1485-1494.

29. Guan WJ, Gao YH, Xu G, et al. Aetiology of bronchiectasis in Guangzhou, southern China. Respirology 2015; 20: 739-748.

30. Murray MP, Turnbull K, MacQuarrie S, et al. Validation of the Leicester Cough Questionnaire in non-cystic fibrosis bronchiectasis. Eur Respir J 2009; 34: 125-131. 
31. Gao YH, Guan WJ, Xu G, et al. Validation of the Mandarin Chinese version of the Leicester Cough Questionnaire in bronchiectasis. Int J Tuberc Lung Dis 2014; 18: 1431-1437.

32. Aliberti S, Masefield S, Polverino E, et al. Research priorities in bronchiectasis: a consensus statement from the EMBARC Clinical Research Collaboration. Eur Respir J 2016; 48: 632-647.

33. Hill AT, Haworth CS, Aliberti S, et al. Pulmonary exacerbation in adults with bronchiectasis: a consensus definition for clinical research. Eur Respir J 2017; 49: 1700051.

34. Murray MP, Pentland JL, Turnbull K, et al. Sputum color: a useful clinical tool in non-cystic fibrosis bronchiectasis. Eur Respir J. 2009; 34: 361-364.

35. Miller MR, Hankinson J, Brusasco V, et al. Standardisation of spirometry. Eur Respir J 2005; 26: 319-338.

36. McDonnell MJ, Aliberti S, Goeminne PC, et al. Comorbidities and the risk of mortality in patients with bronchiectasis: an international multicentre cohort study. Lancet Respir Med 2016; 4: 969-979.

37. Bedi P, Chalmers JD, Goeminne PC, et al. The BRICS (Bronchiectasis Radiologically Indexed CT Score): A Multicenter study score for use in idiopathic and postinfective bronchiectasis. Chest. 2018; 153: 1177-1186.

38. Alzeer AH, Al-Mobeirek AF, Al-Otair HA, et al. Right and left ventricular function and pulmonary artery pressure in patients with bronchiectasis. Chest 2008; 133: 468-73.

39. De Soyza A, Mawson P, Hill AT, et al. BronchUK: protocol for an observational cohort study and biobank in bronchiectasis. ERJ Open Res 2021; 7: 00775-2020.

40. Martinez-García MA, Villa C, Dobarganes Y, et al. RIBRON: The Spanish Online Bronchiectasis Registry. Characterization of the First 1912 patients. Arch Bronconeumol 2021; 57: 28-35.

41. Visser SK, Bye PTP, Fox GJ, et al. Australian adults with bronchiectasis: The first report from the Australian Bronchiectasis Registry. Respir Med 2019; 155: 97-103.

42. Aksamit TR, O'Donnell AE, Barker A, et al. Adult Patients with Bronchiectasis: A First Look at the US Bronchiectasis Research Registry. Chest 2017; 151: 982-992.

43. De Soyza A, Aksamit T, Bandel TJ, et al. RESPIRE 1: a phase III placebo-controlled randomised trial of ciprofloxacin dry powder for inhalation in non-cystic fibrosis bronchiectasis. Eur Respir J 2018; 51: 1702052.

44. Aksamit T, De Soyza A, Bandel TJ, et al. RESPIRE 2: a phase III placebo-controlled randomised trial of ciprofloxacin dry powder for inhalation in non-cystic fibrosis bronchiectasis. Eur Respir J 2018; 51: 1702053.

\section{Tables}


Table 1. Data collection at baseline, exacerbation and follow-up in the BE-China

\section{Baseline}

\section{Mandatory data collection}

Enrollment date

Age

Sex

Body mass index

Socioeconomic status

Smoking history

mMRC score

Sputum color assessment

Exacerbation and hospitalization history in the past 1 year before recruitment

Comorbidities

Spirometry

Imaging tests

Aetiological tests
Annual follow-up

Exacerbations

Follow-up data

Symptoms

Age

Spirometry

Microbiological profiles

Body mass index

Socioeconomic status

Smoking history

mMRC score

Sputum color assessment

Exacerbations and hospitalizations in the past year

Comorbidities

Spirometry

Imaging tests

Updated medical history and laboratory tests to determine the aetiology of bronchiectasis
Treatment

Blood and sputum samples if possible

Blood cell counts

Total IgG, IgA and IgM etc)

Tests for ABPA (total lgE, specific lgE to Aspergillus

Microbiological profiles

Chest physiotherapy

Respiratory medications

Specific aetiological treatment

Vaccination status

Gastroesophageal Reflux Disease Questionnaire

Quality of life-Bronchiectasis Questionnaire

Bronchiectasis Health Questionnaire

Leicester Cough Questionnaire

Hospital Anxiety and Depression Scale
Microbiological profiles

Chest physiotherapy

Respiratory medications

Specific aetiological treatment

Vaccination status

Quality of life-Bronchiectasis Questionnaire

Bronchiectasis Health Questionnaire

Leicester Cough Questionnaire

Hospital Anxiety and Depression Scale

\section{Recommended data collection}

Autoantibody tests (ANA, ENA and ANCA) 
Complement $\mathrm{C} 3$ and $\mathrm{C} 4$

a1-antitrypsin deficiency: serum a1-antitrypsin and genetic tests

Cystic fibrosis: sweating test and genetic tests

Ciliary function test: nasal FeNO, high-speed video analysis, transmission electron microscopy, genetic testing

\section{FeNO}

6 minute walking distance

Arterial blood gas

Echocardiography

Serum, plasma, blood cells, sputum, lung tissue

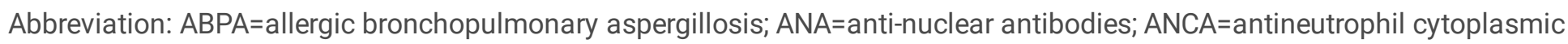

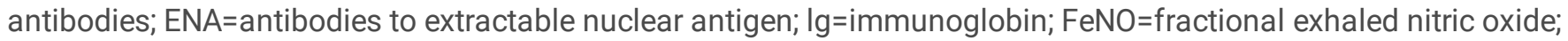
$\mathrm{mMRC}=$ modified British medical research council 
Table 2. Summary of Six ongoing large registry studies on adults with bronchiectasis around the world

\begin{tabular}{|c|c|c|c|c|c|c|c|}
\hline Registry & Main objectives & Settings & $\begin{array}{l}\text { Study } \\
\text { population }\end{array}$ & $\begin{array}{l}\text { Sample } \\
\text { size }\end{array}$ & $\begin{array}{l}\text { Centralized } \\
\text { biobank }\end{array}$ & $\begin{array}{l}\text { Enrollment } \\
\text { timeline }\end{array}$ & Follow-up \\
\hline EMBARC & $\begin{array}{l}\text { To develop a pan- } \\
\text { European, } \\
\text { multicentre } \\
\text { bronchiectasis } \\
\text { registry } \\
\text { incorporating } \\
\text { baseline data } \\
\text { collection with } \\
\text { annual follow-up } \\
\text { data for at least } 5 \\
\text { years; to describe } \\
\text { the demographics, } \\
\text { comorbidities, } \\
\text { aetiology, } \\
\text { medication usage, } \\
\text { resource } \\
\text { consumption, } \\
\text { exacerbations, } \\
\text { microbiology, } \\
\text { severity and } \\
\text { prognosis of } \\
\text { bronchiectasis } \\
\text { across Europe; to } \\
\text { facilitate } \\
\text { multinational } \\
\text { cooperation, within } \\
\text { and outwith } \\
\text { Europe; to } \\
\text { facilitate the } \\
\text { creation of } \\
\text { national registries } \\
\text { in European } \\
\text { countries that } \\
\text { currently do not } \\
\text { have a } \\
\text { bronchiectasis } \\
\text { research } \\
\text { infrastructure }\end{array}$ & $\begin{array}{l}\text { A } \\
\text { minimum } \\
\text { of } 20 \\
\text { European } \\
\text { countries }\end{array}$ & $\begin{array}{l}\text { Adults with a } \\
\text { clinical history } \\
\text { consistent with } \\
\text { bronchiectasis } \\
\text { and computed } \\
\text { tomography } \\
\text { demonstrating } \\
\text { bronchiectasis } \\
\text { affecting one } \\
\text { or } \\
\text { more lobes }\end{array}$ & $\begin{array}{l}\text { Estimated } \\
\text { to enroll } \\
10000 \\
\text { patients } \\
\text { by March } \\
2020 \text {, and } \\
\text { has } \\
\text { enrolled } \\
\text { more than } \\
19,000 \\
\text { patients } \\
\text { as of } \\
\text { October } \\
2021\end{array}$ & Yes & $\begin{array}{l}2012- \\
\text { ongoing }\end{array}$ & $\begin{array}{l}\text { Up to } 5 \\
\text { years }\end{array}$ \\
\hline KMBARC & $\begin{array}{l}\text { To describe of the } \\
\text { clinical } \\
\text { characteristics, } \\
\text { including patient } \\
\text { demographics, } \\
\text { phenotype, } \\
\text { aetiology, } \\
\text { progression, } \\
\text { treatment and } \\
\text { prognosis, of } \\
\text { Korean patients } \\
\text { with } \\
\text { bronchiectasis; to } \\
\text { evaluate of } \\
\text { disease burden, } \\
\text { including use of } \\
\text { medication and } \\
\text { medical resources, } \\
\text { acute } \\
\text { exacerbation, } \\
\text { hospitalisation } \\
\text { and mortality, in } \\
\text { Korean patients } \\
\text { with } \\
\text { bronchiectasis; to } \\
\text { evaluate of the } \\
\text { rare aetiology of }\end{array}$ & $\begin{array}{l}\text { More than } \\
26 \\
\text { hospitals } \\
\text { in South } \\
\text { Korea }\end{array}$ & $\begin{array}{l}\text { Adults with } \\
\text { computed } \\
\text { tomography } \\
\text { demonstrating } \\
\text { bronchiectasis } \\
\text { affecting one } \\
\text { or } \\
\text { more lobes } \\
\text { regardless the } \\
\text { presence of } \\
\text { respiratory } \\
\text { symptoms or } \\
\text { not }\end{array}$ & $\begin{array}{l}\text { At least } \\
1200 \\
\text { patients } \\
\text { over the } \\
\text { study } \\
\text { period }\end{array}$ & No & $\begin{array}{l}\text { August } \\
\text { 2018-- } \\
\text { ongoing }\end{array}$ & $\begin{array}{l}\text { Up to } 5 \\
\text { years }\end{array}$ \\
\hline
\end{tabular}


bronchiectasis (eg,

allergic

bronchopulmonary

aspergillosis,

rheumatoid

arthritis and

tuberculosis); to

elucidation of risk

factors associated

with acute

exacerbation and

prognosis

\begin{tabular}{|c|c|c|c|c|c|c|c|}
\hline BronchUK & $\begin{array}{l}\text { To develop a } \\
\text { multicentre } \\
\text { bronchiectasis } \\
\text { registry } \\
\text { incorporating } \\
\text { baseline data } \\
\text { collection with } \\
\text { annual follow-up } \\
\text { data for at least } 5 \\
\text { years; to facilitate } \\
\text { the creation of a } \\
\text { biobank in } \\
\text { bronchiectasis to } \\
\text { underpin future } \\
\text { mechanistic } \\
\text { studies; to } \\
\text { describe the } \\
\text { treatment patterns } \\
\text { across the UK, } \\
\text { phenotypic data, } \\
\text { comorbidities and } \\
\text { healthcare use; to } \\
\text { facilitate } \\
\text { multinational } \\
\text { cooperation, } \\
\text { especially with } \\
\text { EMBARC, within } \\
\text { academia and } \\
\text { with industry to } \\
\text { develop new } \\
\text { discoveries; to } \\
\text { develop key } \\
\text { partnerships with } \\
\text { experts not } \\
\text { currently working } \\
\text { in bronchiectasis } \\
\text { to optimally use } \\
\text { the datasets. }\end{array}$ & $\begin{array}{l}\text { At least } \\
\text { nine } \\
\text { secondary } \\
\text { care } \\
\text { centres } \\
\text { within UK }\end{array}$ & $\begin{array}{l}\text { Adults with a } \\
\text { clinical history } \\
\text { consistent with } \\
\text { bronchiectasis } \\
\text { and computed } \\
\text { tomography } \\
\text { demonstrating } \\
\text { bronchiectasis }\end{array}$ & $\begin{array}{l}\text { A } \\
\text { minimum } \\
\text { of } \\
1500 \\
\text { patients }\end{array}$ & Yes & $\begin{array}{l}\text { November } \\
2014- \\
\text { ongoing }\end{array}$ & $\begin{array}{l}\text { A } \\
\text { maximum } \\
\text { of } 5 \text { years }\end{array}$ \\
\hline $\begin{array}{l}\text { US } \\
\text { Registry }\end{array}$ & $\begin{array}{l}\text { To support } \\
\text { collaborative } \\
\text { research and } \\
\text { assist in the } \\
\text { planning of multi- } \\
\text { center clinical } \\
\text { trials for the } \\
\text { treatment of NTM } \\
\text { and non-CF } \\
\text { Bronchiectasis; to } \\
\text { provide better } \\
\text { insight into the } \\
\text { study of the } \\
\text { different types of } \\
\text { Bronchiectasis, as } \\
\text { well as the } \\
\text { pathophysiology } \\
\text { of the disorder }\end{array}$ & $\begin{array}{l}17 \text { active } \\
\text { sites in the } \\
\text { United } \\
\text { States }\end{array}$ & $\begin{array}{l}\text { Adults with a } \\
\text { physician- } \\
\text { established } \\
\text { diagnosis of } \\
\text { bronchiectasis }\end{array}$ & $\begin{array}{l}\text { Estimated } \\
\text { to enroll } \\
5000 \\
\text { patients, } \\
\text { and has } \\
\text { enrolled } \\
\text { more than } \\
4000 \\
\text { patients } \\
\text { as of } \\
\text { October } \\
2021\end{array}$ & Unknown & $\begin{array}{l}2007- \\
\text { ongoing }\end{array}$ & $\begin{array}{l}\text { Up to } 20 \\
\text { years }\end{array}$ \\
\hline
\end{tabular}

Australian To understand the At least 14 Australian Unknow Unknown 2015- Up to 5

Page 16/19 


\begin{tabular}{|c|c|c|c|c|c|c|c|}
\hline Registry & $\begin{array}{l}\text { cause, incidence } \\
\text { and prevalence of } \\
\text { bronchiectasis; to } \\
\text { explore the burden } \\
\text { of illness and of } \\
\text { treatment; to } \\
\text { support the } \\
\text { exploration of } \\
\text { innovative } \\
\text { treatments; to } \\
\text { improve quality of } \\
\text { life and offer } \\
\text { opportunities for } \\
\text { consumer } \\
\text { engagement; to } \\
\text { identify the } \\
\text { economic impact } \\
\text { of bronchiectasis } \\
\text { on an individual } \\
\text { and our } \\
\text { community; to } \\
\text { maximise equity } \\
\text { of access for all } \\
\text { Australians to } \\
\text { bench marked, } \\
\text { evidence-based } \\
\text { management for } \\
\text { bronchiectasis }\end{array}$ & $\begin{array}{l}\text { sites } \\
\text { across the } \\
\text { Australian } \\
\text { mainland }\end{array}$ & $\begin{array}{l}\text { adults and } \\
\text { children with a } \\
\text { physician } \\
\text { diagnosis of } \\
\text { bronchiectasis } \\
\text { with abnormal } \\
\text { bronchial } \\
\text { dilatation } \\
\text { demonstrated } \\
\text { on computed } \\
\text { tomography } \\
\text { chest scan }\end{array}$ & & & ongoing & years \\
\hline $\begin{array}{l}\text { Indian } \\
\text { Registry }\end{array}$ & $\begin{array}{l}\text { To advance } \\
\text { research and } \\
\text { improve clinical } \\
\text { care for patients } \\
\text { with non-cystic } \\
\text { fibrosis } \\
\text { bronchiectasis in } \\
\text { India }\end{array}$ & $\begin{array}{l}\text { At least } 31 \\
\text { centres } \\
\text { across } \\
\text { India }\end{array}$ & $\begin{array}{l}\text { Adults with a } \\
\text { clinical history } \\
\text { consistent with } \\
\text { bronchiectasis } \\
\text { and computed } \\
\text { tomography } \\
\text { demonstrating } \\
\text { bronchiectasis } \\
\text { affecting one } \\
\text { or } \\
\text { more lobes }\end{array}$ & $\begin{array}{l}\text { Unknow } \\
\text { (has } \\
\text { enrolled } \\
\text { more than } \\
2195 \\
\text { patients } \\
\text { as of } \\
\text { September } \\
\text { 2017) }\end{array}$ & Unknown & $\begin{array}{l}\text { May } 2015 \\
\text {-ongoing }\end{array}$ & $\begin{array}{l}\text { Up to } 5 \\
\text { years }\end{array}$ \\
\hline RIBRON & $\begin{array}{l}\text { To obtain } \\
\text { information from } \\
\text { bronchiectasis } \\
\text { patients to } \\
\text { improve the } \\
\text { knowledge of the } \\
\text { disease in Spain; } \\
\text { to facilitate and } \\
\text { promote } \\
\text { multicenter and } \\
\text { multidisciplinary } \\
\text { research in } \\
\text { bronchiectasis; to } \\
\text { identify groups of } \\
\text { patients who may } \\
\text { be candidates for } \\
\text { future clinical } \\
\text { trials; to assess } \\
\text { the follow-up of } \\
\text { Spanish } \\
\text { bronchiectasis } \\
\text { clinical guide-lines } \\
\text { and } \\
\text { recommendations } \\
\text { in the attempt to } \\
\text { standardize and } \\
\text { improve patient } \\
\text { management }\end{array}$ & $\begin{array}{l}43 \\
\text { hospitals } \\
\text { located } \\
\text { throughout } \\
\text { Spain }\end{array}$ & $\begin{array}{l}\text { Adults with a } \\
\text { clinical picture } \\
\text { consistent with } \\
\text { bronchiectasis } \\
\text { of any etiology } \\
\text { (including } \\
\text { cystic fibrosis) } \\
\text { diagnosed } \\
\text { with chest } \\
\text { high-resolution } \\
\text { computed } \\
\text { tomography }\end{array}$ & $\begin{array}{l}\text { Unknow } \\
\text { (has } \\
\text { enrolled } \\
\text { more than } \\
2300 \\
\text { patients } \\
\text { as of July } \\
2019 \text { ) }\end{array}$ & No & $\begin{array}{l}\text { February } \\
2015- \\
\text { ongoing }\end{array}$ & Unknow \\
\hline
\end{tabular}


Figures

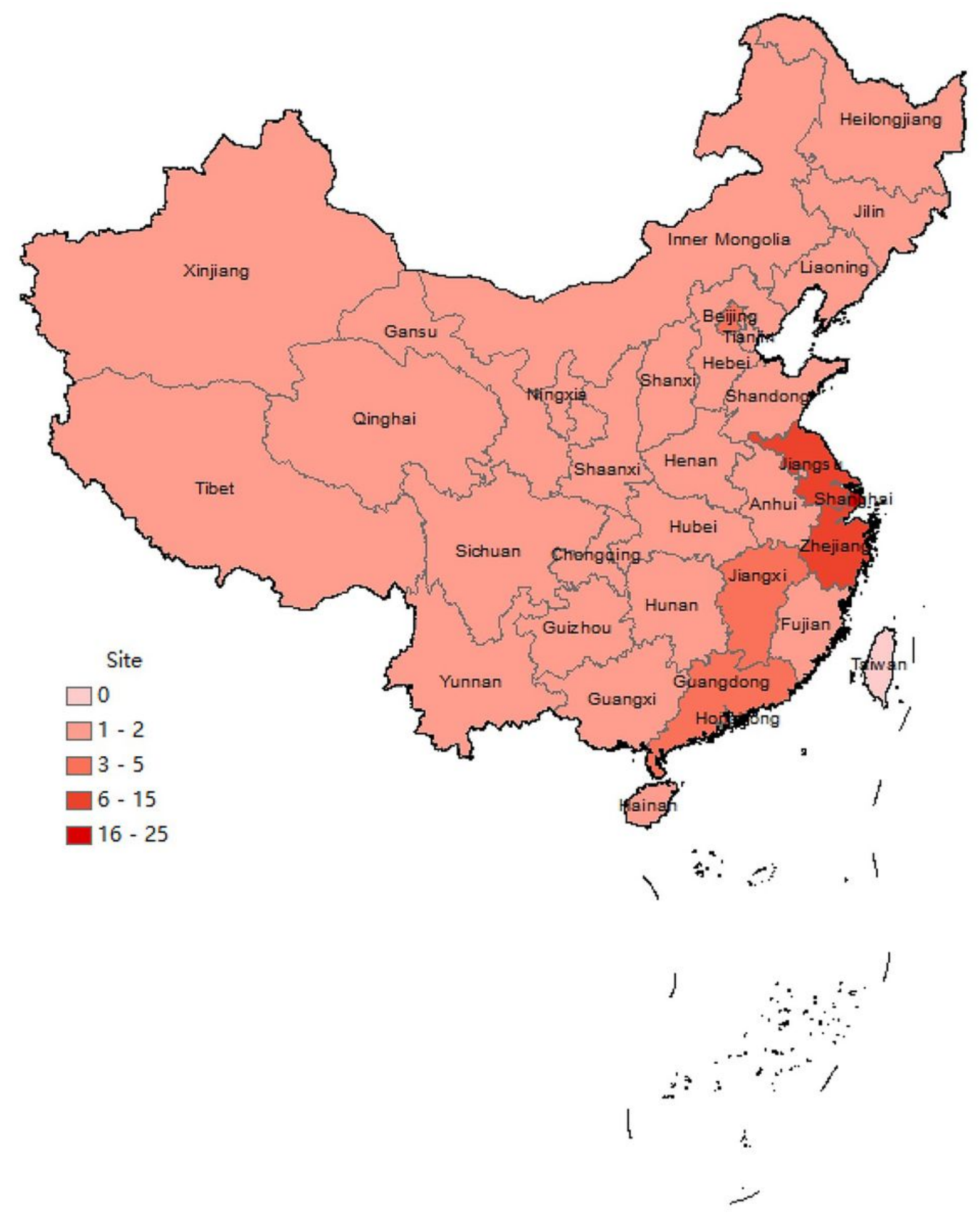

Figure 1

The number of 91 participating medical centers in the BE-China and their locations across China. 


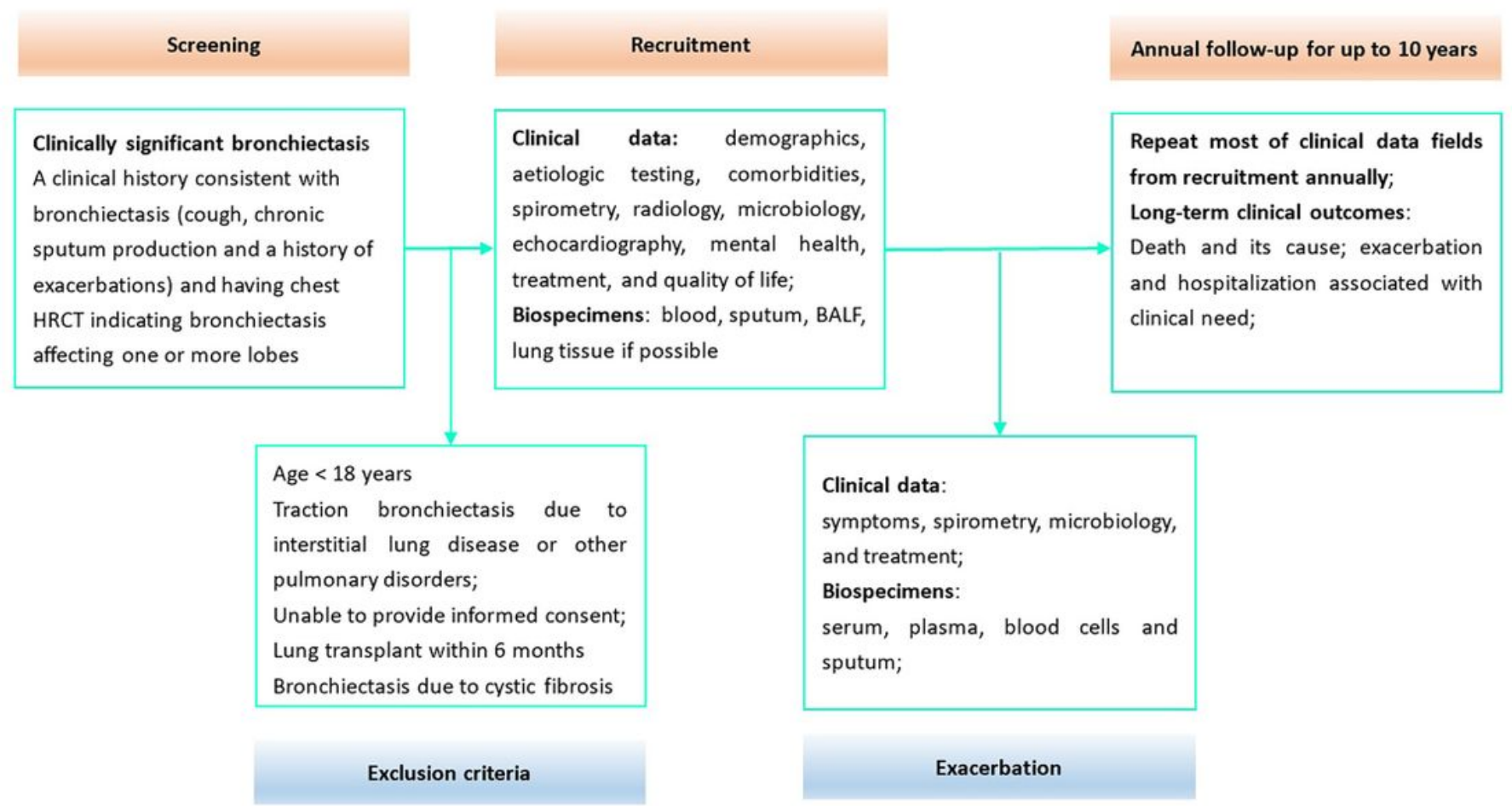

\section{Figure 2}

Study flowchart of the BE-China. 